\title{
PROGRESS AT THE SEOUL NATIONAL UNIVERSITY AMS FACILITY
}

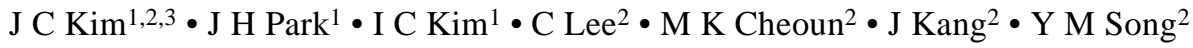

\begin{abstract}
The accelerator mass spectrometry facility at the Seoul National University (SNU-AMS) was completed in December 1998 and a report was presented at the Vienna AMS conference in September 1999. At the conference, we described the basic components of our accelerator system and reported the results of the performance test. Since then, extensive testing of the accuracy and reproducibility of the system has been carried out, and about 200 unknown samples have been measured so far. We obtained a precision of $4 \%$ o for modern samples, and an accuracy of approximately 40 yr was demonstrated by analyzing samples that were previously dated with a conventional technique and by other AMS laboratories. We present these results here, together with detailed descriptions of our data-taking and analysis procedures.
\end{abstract}

\section{INTRODUCTION}

We have been operating our new accelerator mass spectrometry (AMS) facility during the past year. It has been quite a challenging task to maintain an AMS machine like ours in a country with little available expertise in accelerator handling. In early 1999, we began to analyze samples provided by outside users. During one year's operation, about 200 unknown samples have been measured so far. In the meantime, background and chemical blank studies have been carried out. At present, the oldest age we obtained for the samples treated by our sample preparation is $41 \mathrm{ka}$. This will be improved in the near future by introducing a new combustion method using an element analyzer. In this contribution, we present general laboratory procedures, such as sample preparations, data taking, age calculation, and calibration. In addition, we discuss important issues related to the accuracy and quality of measurements emerging from the Seoul National University AMS facility (SNU-AMS).

Immediately following the acceptance tests (Kim et al. 2000), an additional performance test was made using QA (quality assurance) samples from Beta Analytic. Table 1 shows the results of this test, which are in very good agreement; 6 out of 7 are within an error of $1 \sigma$. Although the machine produced stable and reliable results, there have been many technical problems as shown in Figure 1. Most of them were minor in nature and were easily corrected in a day or two. However, it is worth mentioning two major repair works, which resulted in a long machine downtime.

The first was a failure of the scan mechanism of the 846 ion source. The cause of this problem turned out to be moisture collecting around the Syltherm cooling lines and emerging into the servomotor unit, which caused erratic functioning. It took us considerable time and effort to locate the source of the problem. Several hardware items, such as the CPU of the main computer, the power supply of the source computer, servomotor controllers, and also a servomotor, had to be replaced. It took three months to complete repairs.

The second major repair concerned the Ar gas stripper system. The motor-generator system was out of order. It supplies electric power to the turbo molecular pump, which circulates Ar gas in the stripper canal. The pressure tank had to be opened, and the bearings assembly had to be replaced. This repair required a period of three weeks of pressure tank opening.

\footnotetext{
${ }^{1}$ Department of Physics, Seoul National University, Seoul 151-742, Korea

${ }^{2}$ Inter-University Center for Natural Science Research Facility, Seoul National University, Seoul, Korea

${ }^{3}$ Corresponding author. Email: jckim@phya.snu.ac.kr.
}

(C) 2001 by the Arizona Board of Regents on behalf of the University of Arizona RAdiocarbon, Vol 43, Nr 2A, 2001, p 163-167

Proceedings of the 17th International ${ }^{14} \mathrm{C}$ Conference, edited by I Carmi and E Boaretto 
Table 1 Results of SNU-AMS measurements for the samples provided by Beta Analytic

\begin{tabular}{lcc}
\hline & \multicolumn{2}{c}{ BP $(1 \sigma$ uncertainty $)$} \\
\cline { 2 - 3 } Sample ID & Beta's QA value & SNU-AMS results \\
\hline SE1-1 & $145.2(0.6)^{\mathrm{a}}$ & $142.9(0.6)^{\mathrm{a}}$ \\
SE1-2 & $41,800(1300)$ & $42,200(700)$ \\
SE1-3 & $8970(50)$ & $9100(120)$ \\
SE1-4 & $12,810(50)$ & $12,900(110)$ \\
SE1-5 & $34,980(520)$ & $35,000(330)$ \\
SE1-6 & $1130(40)$ & $1160(40)$ \\
SE1-7 & $23,060(130)$ & $22,900(600)$ \\
\hline
\end{tabular}

${ }^{\mathrm{a} p M C}$ value

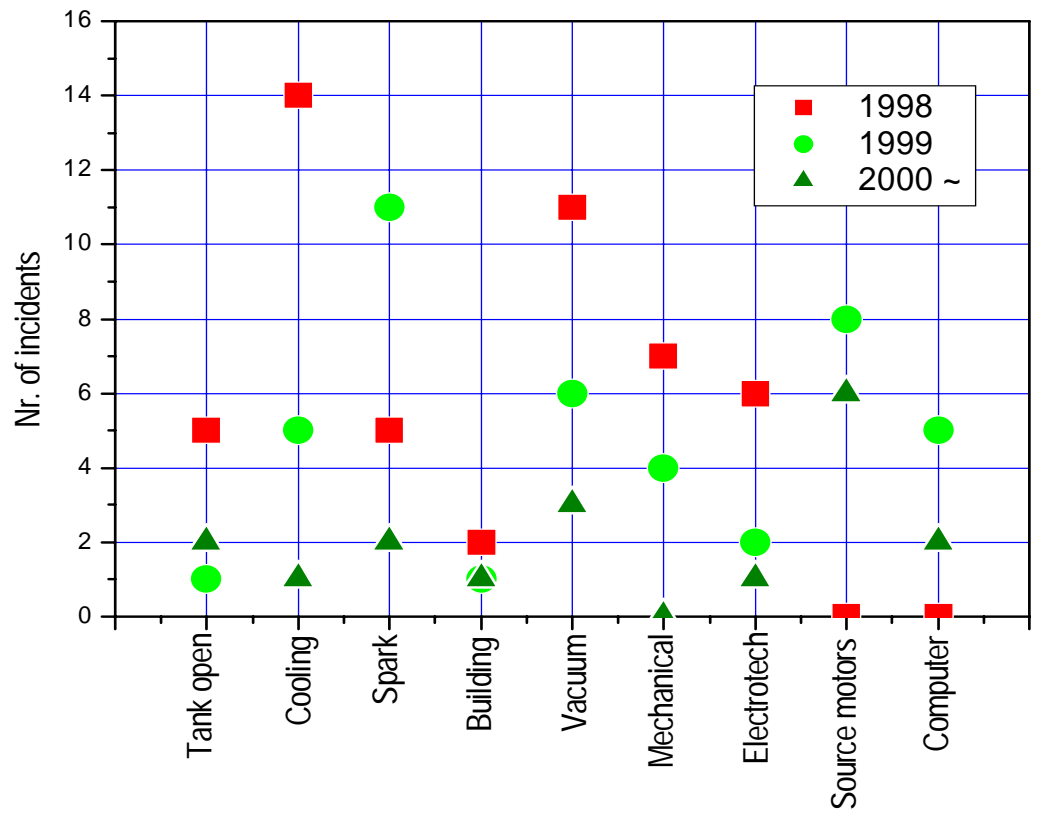

Figure 1 Overview of SNU-AMS technical problems

\section{SAMPLE HANDLING AND MEASUREMENT PROCEDURE}

Routine samples such as charcoal, wood, and grain were first examined for contamination: plant roots were removed, and pieces of charcoal were picked by hand or sieved out of the soil matrix. The wood samples were cut into pieces 10-40 microns in size, and the charcoal was crashed into 10-60micron-sized pieces. Then, after cleaning in an ultrasonic bath to remove adherent particles, the standard AAA (acid-alkali-acid) method (Olsson 1980) was applied as a further pretreatment.

Peat samples were, after physical cleaning, subjected to $1 \mathrm{M}$ of $\mathrm{HCl}$ at $80{ }^{\circ} \mathrm{C}$ for $24 \mathrm{hr}$ to remove contaminants such as carbonates, fulvic acids, etc. Next, alkali soluble extracts were obtained by applying $0.5 \% \mathrm{NaOH}$ at room temperature for another $24 \mathrm{hr}$. These extracts were filtered and precipitated by applying $1 \mathrm{M}$ of $\mathrm{HCl}$ at $80^{\circ} \mathrm{C}$ for $3 \mathrm{hr}$. Finally, the solid precipitate was cleaned with cold distilled water and dried in the oven for $8 \mathrm{hr}$ at $120^{\circ} \mathrm{C}$. 
Ten to $20 \mathrm{mg}$ of pretreated sample material was placed in a quartz tube containing approximately $1 \mathrm{~g}$ $\mathrm{CuO}$. Silver wire was added as a scrubber for sulphur, and the tubes were evacuated by a sorption pump to approximately $2 \times 10^{-3} \mathrm{mb}$ and sealed with a glassblowing torch. For complete combustion of the sample to $\mathrm{CO}_{2}$, the sealed samples were heated in a muffle furnace at $850{ }^{\circ} \mathrm{C}$ for $2 \mathrm{hr}$. After combustion, the quartz tubes were broken inside a flexible bellows, and the $\mathrm{CO}_{2}$ was transferred cryogenically to transport vessels of volume $11 \mathrm{~cm}^{3}$. The typical combustion yield is $400 \mathrm{mb} \mathrm{CO}_{2}$, which corresponds to approximately $3 \mathrm{mg}$ of elemental carbon.

The catalytic reduction method (Vogel et al. 1984) is now a standard method used by many AMS ${ }^{14} \mathrm{C}$ laboratories. Our system is adopted from the Leibniz Labor, Kiel, Germany (Nadeau et al. 1997). The $\mathrm{CO}_{2}$ is reduced to carbon by $\mathrm{H}_{2}$ using $\mathrm{Fe}$ as a catalyst at $550{ }^{\circ} \mathrm{C}$ in a $3 / 8^{\prime \prime}$ quartz reaction tube. The $\mathrm{Fe}$ is preheated and activated by oxidation with $0.5 \mathrm{~atm} . \mathrm{O}_{2}$ at $500{ }^{\circ} \mathrm{C}$ for $30 \mathrm{~min}$ and subsequently reduced with $0.5 \mathrm{~atm} . \mathrm{H}_{2}$ at $400{ }^{\circ} \mathrm{C}$ during $30 \mathrm{~min}$. The sample $\mathrm{CO}_{2}$ is cryogenically transferred from the transport vessel into the reactor, pre-evacuated to approximately $1 \times 10^{-3} \mathrm{mb}$ by a turbo-molecular pump, and $\mathrm{H}_{2}$ is introduced into the reactor to the total pressure which is 2.5 times that of $\mathrm{CO}_{2}$.

The reaction is initiated by placing a preheated oven at $630{ }^{\circ} \mathrm{C}$ over the reactor. A cold trap of $-20{ }^{\circ} \mathrm{C}$ cooled by a Peltier element removes the water vapor from the reaction. The complete reaction takes about 8 hours.

The samples are mixed with Fe powder, and pressed into a 2-mm-diameter cylindrical hole in the $\mathrm{Al}$ target holder. Using targets made this way, the 846 Ion source produces approximately $20 \mu \mathrm{A} \mathrm{C}$, and analyzed ${ }^{13} \mathrm{C}$ beams of about $200 \mathrm{nA}$ in the Faraday cup after the $110^{\circ}$ magnet. The targets are measured twice at nine different positions around a $1 \mathrm{~mm}$ diameter circle for 40 seconds per position. Such measurements are repeated three times per target. The standard deviations are calculated from the statistical results for these three measurements. This measuring time is usually sufficient to obtain \pm 40 yr $1 \sigma$ uncertainty for modern samples. Samples prepared from Oxalic-II are used as a standard. We measure one standard per three unknown samples.

The ${ }^{12} \mathrm{C}$ and ${ }^{13} \mathrm{C}$ currents are measured in Faraday-cups placed just after the $110^{\circ}$ magnet in the highenergy beam line of our AMS system. The ${ }^{14} \mathrm{C}^{3+}$ ions are detected in the ionization chamber, simultaneously with ${ }^{12} \mathrm{C}$ and ${ }^{13} \mathrm{C}$ taking advantage of the recombinator system built for this new generation Tandetron AMS system (Purser et al. 1988; Gottdang et al. 1995). The conventional radiocarbon age, $\mathrm{BP}$, is obtained from the measured ${ }^{14} \mathrm{C} /{ }^{12} \mathrm{C}$ ratios, for samples and standards. Isotopic fractionation is determined from ${ }^{13} \mathrm{C} /{ }^{12} \mathrm{C}$ ratios for samples and standards, using the formulas as given by Stuiver and Polach (1977) and, more recently, by Mook and van der Plicht (1999).

For background correction, the ${ }^{14} \mathrm{C} /{ }^{12} \mathrm{C}$ ratio of the chemistry blank is subtracted from the ${ }^{14} \mathrm{C} /{ }^{12} \mathrm{C}$ ratio of both the standards and samples. Our chemistry blank are prepared from fossil wood.

\section{RESULTS}

\section{Reference Samples}

We use Oxalic II as the standard. In addition, we also use IAEA C3 (cellulose) and C5 (wood) reference material (Rozanski et al. 1992) for quality control of our sample preparation chemistry. Their ${ }^{14} \mathrm{C}$ contents as measured in our laboratory are $129.39 \pm 0.76 \mathrm{pMC}$ and $23.81 \pm 0.39 \mathrm{pMC}$, while their recommended values are $129.41 \pm 0.06 \mathrm{pMC}$ and $23.05 \pm 0.02 \mathrm{pMC}$. Two additional archaeological samples have assured us of the quality of our sample preparation; for example, a charcoal sample from a Bronze Age archaeological site from the southern part of Korea, Daipyung-ri, was 
previously measured by ISOTRACE, the Canadian Center of Accelerator Mass Spectrometry at the University of Toronto, Canada as $2280 \pm 60 \mathrm{BP}$ (sample ID TO-6770). The same sample was remeasured in our laboratory just after machine installation, yielding an age of $2360 \pm 50 \mathrm{BP}$ (sample ID SNU99-01), showing excellent agreement. Another charcoal sample was submitted to us in the very early stage of our AMS operation. It was again a charcoal sample gathered at a well-known archaeological site discovered recently in suburban Seoul, an ancient military fortress dating from $550 \mathrm{AD}$. Our measured result for this sample was $1490 \pm 50 \mathrm{BP}$ (sample ID SNU99-02), again demonstrating good agreement.

Results on these samples established the reliability of our ${ }^{14} \mathrm{C}$ dating procedure and its capability to perform routine dating. Since that time about 200 samples of archaeological and geological interest have been measured. An exemplary result from our regular batch is shown in Figure 2. In the figure, the instrumental error, i.e., internal error is always less than the external error, which indicates that no significant systematic errors are contributing to the measurement. BP errors of \pm 40 are easily obtained with the normal measuring procedure mentioned in the previous section.

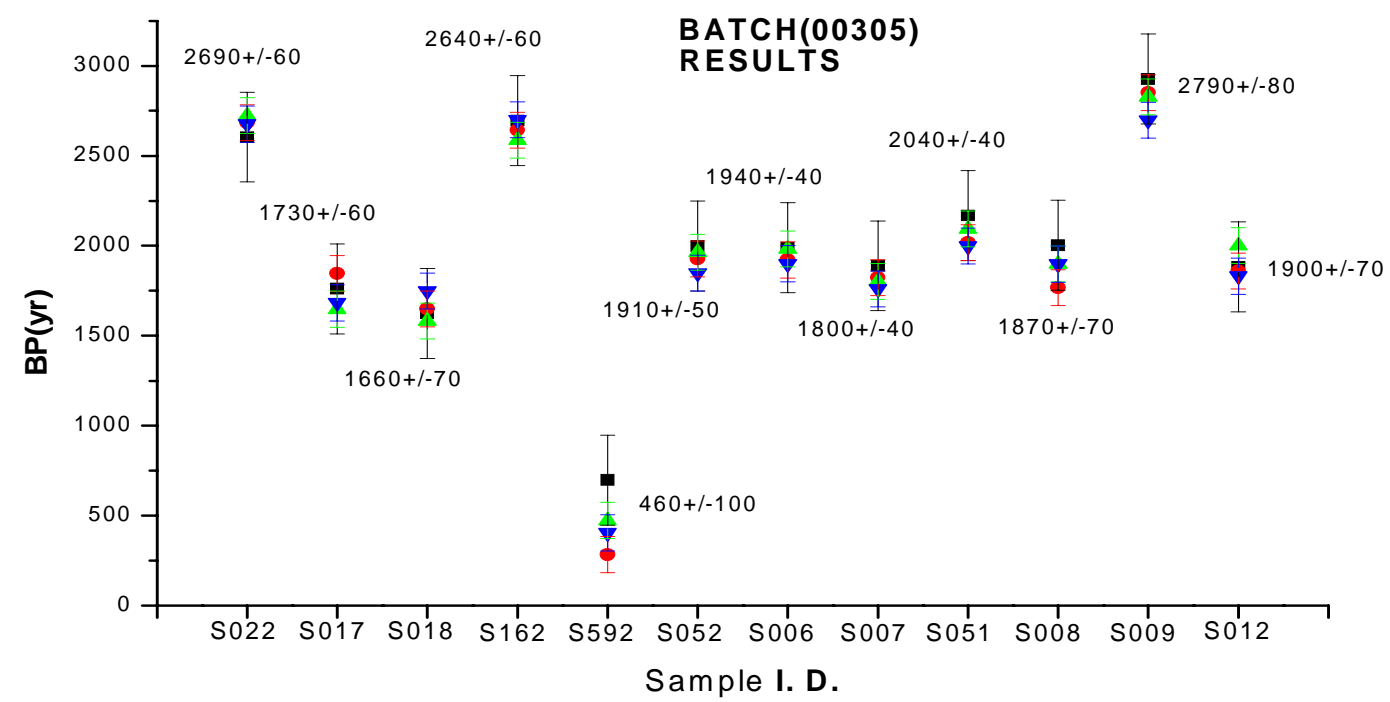

Figure 2 The results from typical batch run. For each sample, of which the ID is denoted in the abscissa, measurements were made three times and the resulting BP values are shown in the ordinate. Standard deviations followed by [+/-] are obtained by procedures described on page 164 .

\section{Background}

The chemical blank value we obtained thus far by using fossil wood materials is $0.6 \mathrm{pMC}$, which corresponds to an age of approximately $41 \mathrm{ka}$. On the other hand, the machine background investigated by using a blank $\mathrm{Al}$ target is approximately $70 \mathrm{ka}$. We also evaluated our standard sample with respect to Oxalic-I prepared by Beta Analytic, and observed that the $\mathrm{pMC}$ value of our standard sample, Oxalic-II, prepared by our chemistry is 133.4 , which is a little too low compared to the recommended value of 134.06 (Stuiver 1983). To improve this situation and also push the limit of our BP measurement beyond $50 \mathrm{ka}$, we are planning to adopt the method of dynamic flash combustion system utilizing a commercially available Element Analyzer system, as has been successfully employed at other AMS laboratories (Morgenroth et al. 2000; Aerts-Bijma et al. 1997). 


\section{CONCLUSION}

SNU-AMS is now fully operational, and the basic laboratory procedures are well established. However, improvements are required in the area of sample preparation. Further lowering backgrounds from the present level will probably be achieved by introducing a new combustion system. The throughput will also be increased with this system, together with a multiple reduction line, a 10-fold parallel system, which is under construction at our laboratory.

\section{AKNOWLEDGMENTS}

This work was supported by the Korea Engineering and Science Foundation (KOSEF grant no. 98070206013), and also in part by the Nuclear R\&D Program (MOST 1999).

\section{REFERENCES}

Aerts-Bijma ATh, Meijer HAJ, van der Plicht J. 1997. AMS sample handling in Groningen. Nuclear Instruments and Methods in Physics Research B123:221-5.

Gottdang A, Mous DJW, van der Plicht J. 1995. The HVEE ${ }^{14} \mathrm{C}$ system at Groningen. Radiocarbon 37(2): 649-56.

Kim JC, Lee CH, Kim IC, Park JH, Kang J, Cheoun MK, Kim YD, Moon CB. 2000. A new AMS facility in Korea. Nuclear Instruments and Methods B172:13-7.

Mook WG, van der Plicht J. 1999. Reporting ${ }^{14} \mathrm{C}$ activities and concentration. Radiocarbon 41(3): 227-39.

Morgenroth G, Kerscher H, Kretschmer W, Klein M, Rechel M, Wrzosok I. 2000. Improved sample preparation techniques at the Erlangen AMS-facility. Nuclear Instruments and Methods in Physics Research B172: 416-23.

Nadeau MJ, Schleicher M, Grootes PM, Erleneuser H, Gottdang A, Mous DJW, Sarnthein JM, Willkomm H. 1997. The Leibniz-Labor AMS facility at the Christian-Albrecht-University, Kiel, Germany. Nuclear In- struments and Methods in Physics Research B123:2230.

Olsson IU. 1980. ${ }^{14} \mathrm{C}$ in extractives from wood. Radiocarbon 22(2):515-24.

Purser KH, Smick TH, Litherland AE, Beukens RP, Kieser WE, Kilius LR. 1988. A third generation ${ }^{! 4} \mathrm{C}$ accelerator mass spectrometry. Nuclear Instruments and Methods in Physics Research B135:284-91.

Rozanski K Stichler W, Gonfiantini R, Scott EM, Beukens RP, Kromer B, van der Plicht J. 1990. The IAEA ${ }^{14} \mathrm{C}$ Intercomparison Exercise 1990. Radiocarbon 34(3):506-19.

Stuiver M, Polach HA. 1977. Discussion: reporting of ${ }^{14} \mathrm{C}$ data. Radiocarbon 19(3):355-63.

Stuiver M. 1983. Buisness meeting. Radiocarbon 25(2): 793-5.

Vogel JS, Nelson DE, Southon JR. 1987. ${ }^{14} \mathrm{C}$ background levels in an accelerator mass spectrometry system. $R a$ diocarbon 29(3):323-33. 